International Journal of Advanced Biological and Biomedical Research

Available online at http:www.ijabbr.com

Volume 7, Issue 3 (2019) pp. 213-224

Original Article

\title{
Factors Affecting the Use of Sustainable Agriculture in Iran's Potato Cultivars
}

\author{
Tahmineh Toliatkashani, Maryam Omidi Najaf Abadi, Farhad Lashgarara
}

Department of Agricultural Extension and education, Science and Research Branch, Islamic Azad University, Tehran, Iran

*Corresponding Author E-mail: maryomidi@gmail.com

Received: 5 February 2019, Revised: 10 March 2019, Accepted: 15 March 2019

\begin{abstract}
Current research examines the economic, social, cultural, policy, educational and promotional factors in using sustainable agriculture operations. Research is an applied type and its method is correlation. The statistical population consisted of 102 members of Iran Potato Cultivars. Data were collected using a census method and a questionnaire was used. The Cronbach's alpha coefficient was obtained among $0.4723 .0 \pm 0.946 / 0$, indicating the reliability of this tool. Statistical analysis of data was performed using SPSS20 software. The results of regression analysis indicated that three variables: economic factors, policy factors, educational and promotional factors were the most important independent variables affecting the dependent variable of sustainable agriculture, that was $42.1 \%$ of the variation of dependent variable (implementation of sustainable agricultural activity) that explain the research.

Also the results indicated that the economic factor variable with the beta coefficient equal to 0.339 is the most important variable affecting the implementation of sustainable agricultural practices. The variable policy making factor with a regression coefficient of 0.146 is the least important factor affecting the implementation of sustainable agricultural operations.
\end{abstract}

Key words: Sustainable agriculture, Potato seed producers.

\section{Introduction}

Agriculture has greatly changed the structure and operation of natural ecosystems as the most important way of providing human food. Human exploitation of natural resources is usually unilateral and extrinsic, and the exploitation of these resources without observing its protective aspects, and only according to the provision of short-term benefits. The growing population and the food shortage crisis have caused excessive utilization of natural resources and, consequently, a deterioration in the biological balance. Excessive use of chemicals in agriculture has led to various environmental problems. Sustainable agriculture refers to the proper management of agricultural resources that is used to meet the changing needs of humans, while preserving and even improving the natural resources as well as the quality of the environment. Sustainable agriculture is beneficial and sustainable, according to the preservation of natural resources. This method of agriculture is the most economical 
and, at the same time, the most beneficial way to use energy and convert it into agricultural products, without destroying soil fertility and the quality of the environment (Mousavi, 2015).

In sustainable agriculture as a knowledge system operation through a combination of natural processes of agricultural production and the use of more knowledge and skills of farmers, better use of internal resources, farm work is so self-reliance and capacity of farmers to improve and upgrade (Khosrou Beygi et al., 2012).

With the advent of toxins in food, the awareness and sensitivity of people to the destructive consequences of excessive use of chemical fertilizers and pesticides on the environment has increased. During the past few decades, excessive use of chemical pesticides to control pests and plant diseases has caused many problems for humans, the environment and other living organisms in natural habitats. Irrigation and rain are washed and transferred to groundwater, among that the use of high-risk toxins will also destroy other ecological ecosystems (Bigdeli et al., 2010).

In recent decades the use of chemical inputs cause environmental problems serious, including water pollution, degradation of agricultural products and reducing soil fertility is sustainable agriculture according to the use of bio-fertilizers to eliminate or reduce significantly the consumption of chemical inputs, a desirable solution is to overcome these problems (Farouh Tat et al., 2013).

In Iran, for the use of contaminated water or the use of fertilizers and chemical pesticides in the production of agricultural products, social and health costs for consumers of agricultural products and government are increasing. We usually hear that for the inability to control the agricultural waste, fertilizers and agricultural toxins enter the waters and rivers and threaten the inhabitants of many cities in the country. The official calculations and figures provided by the researchers about the state of the natural resources and environment of Iran are very disappointing. Iran has the second largest world in terms of erosion and degradation of fertile land and natural resources after Australia, with a destruction and erosion of 33 tons of soil per hectare, one of the main reasons for the excessive use of fertilizers and pesticides in agriculture (Enayati Rad et al., 2009).

According to various official officials, 90 percent of the use of controlled aquatic resources is consumed by the general population. Although, many believe that, despite the low productivity of agriculture in Iran, there is no need for either a full-fledged agricultural approach to be considered as a major revolution in cultivation practices, according to the World Food Organization (FAO) Water consumption in Iran's agricultural sector is 22\% more than the global average. According to the same report, in the world, the amount of agricultural production is about $2.5 \mathrm{~kg}$ of water per cubic meter, while the amount in Iran is about one kilogram and the gross national product is only among 20 and 40 cents. The cost of a cubic meter of water is estimated in the agricultural sector, with an average global price of about $\$ 2$ or even more.

Approximately 22 to 24 thousand tons of poison are consumed annually in the country, this amount of poison with the amount of efficient material that is used when we calculate an average of 562 grams of toxic per hectare of agricultural land per country, while The average active ingredient in poison in the world is one kilogram and in the United States is more than this. Food security consists of two parts: adequate food and health. The production of organic products is in good condition, i.e., in areas where there is no use of 
any type of chemical fertilizer for 3 years, and not irrigated by the water containing the feedstock (Ebtali, 2015).

In the provinces like Isfahan, the amount of phosphorus fertilizers used is $100 \mathrm{~kg} / \mathrm{ha}$ of ammonium phosphate (depending on the soil and plant requirement), pure potash among 250 and $300 \mathrm{~kg}$ ha-1, nitrogen fertilizers and ammonium nitrate granules in the range of 160 to $220 \mathrm{~kg}$ ha-1 (Depending on the cultivar and the level of the foliage). Also, the consumption of monensin fungicide in a kilogram with one ton of seed at the time of cultivation is mixed. The fungus is used to prevent spraying $2 \mathrm{~kg}$ per hectare every 12 days, and it takes 3-4 steps. Daconyl semen is used in the presence of fungal contamination of 2 to 2.5 liters per hectare. From various types of insecticides, depending on the type of pest, diamethate is 2 liters per hectare and acetate pride 300 grams per hectare, as well as avant to fight potato worm (Sajjadi et al, 2017).

Kurdistan province, according to soil experiments, uses about $100 \mathrm{~kg}$ of ammonium phosphate per hectare - among 200 to $300 \mathrm{~kg}$ of potassium sulfate per hectare and $200 \mathrm{~kg}$ of urea per hectare for seed potato cultivation. (Niyazi et al, 2016).

Markazi province usually mix uranium fertilizer 20 days before cultivation with granular soil, or use $200 \mathrm{~kg}$ ha-1 as fertilizer in soil tillage - $100 \mathrm{~kg}$ ha-1 potash fertilizer and $150 \mathrm{~kg}$ ha-1 phosphorus fertilizer (Sarikhani et al, 2016).

* Percentage of potatoes per capita in the world, Iran and some improving countries (19612008).

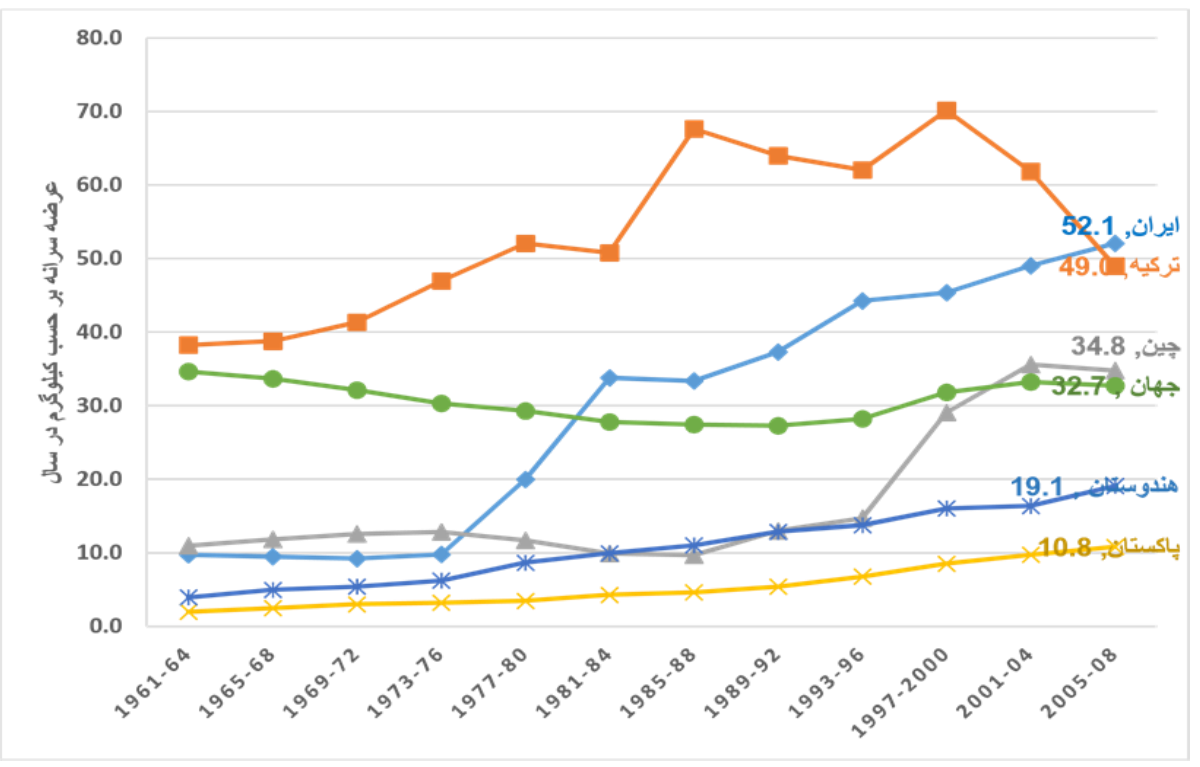

Today, one of the main causes of the tsunami in Iran is the excessive use of fertilizers and poisons in agricultural production.

Following the widespread use of chemical inputs in the production of agricultural products, natural resources and reserves of the country have been subject to destruction. There has been a proliferation of reports on the proliferation of illnesses caused by excessive use of pesticides and fertilizers in agricultural production every day in various media, Pesticides and chemical fertilizers in various parts of the country, in addition to irreparable damage to the environment and life of living organisms, are considered as dangerous contaminants of water and soil that remain in the environment for several years, and improper use of these materials will increase the statistics of individuals Afflicted. The cancer has been in the 
country and its alarm has long been heard, so, in addition to environmental and health experts, health and medical experts also emphasize the importance of proper use of these materials, since the Iranian potato producers' Possibility of monitoring and implementation of fertile lands for the cultivation of strategic potato products, and the supply of products in international markets, can provide a strong incentive to implement sustainable agricultural practices among farmers in the areas concerned. So, the main issue of this research is to investigate the factors affecting the sustainable agriculture operation of the case study in the center of seed potato producers in Iran (Hasan Abadi, 1395).

\section{Research Methodology}

The method of this research is according to the aim of solving the problem of common agricultural use, that causes great damage, human, environmental and production. This research looks for the plan the idea of implementing sustainable agricultural practices in order to achieve its practical results, that is according to the implementation process, and data analysis is carried out using statistical methods. The final report is a statistical aspect and is expressed in terms of numbers. In terms of logic, it is analogous for the starting point of the test is the theory of sustainable agricultural implementation, the inference and conclusion of that is in its entirety. The time of the research is longitudinal in terms of time and it is retrospective for the reason for this problem is the use of unsustainable methods in the implementation of agricultural operations in the past and its consequences have become a problem for humans in the present time. For the hypothesis of the method, this research is analytical and for of the fact that solving one of the problems that human beings face, we are not allowed to control and interfere in the research conditions. It is a quasiexperimental category. Since it examines the factors affecting the use of sustainable agricultural operations in the center of seed potato producers, it is a type of correlation that influences the relationships of variables in a group. Measurement with 5 Likert scale is carried out.

\section{Statistical community}

The statistical population in this research includes the members of the potato producers' center operating in eight provinces of markazi, Isfahan, Chaharmahal-Bakhtiari, Khorasan, Fars, Kordestan, Hamedan, Ardebil. Their views and experiences can be found in planning, policy making and the implementation of sustainable agriculture operations is efficient in the center, and their number is $102(\mathrm{~N}=102)$. In this research, for the small size of the population, there is no need for sampling. The census method was used to collect information from the statistical society. The census is the extraction of information from all instances of the statistical society.

\section{Research tool}

The tool used in this research is to collect information from the questionnaire. The questionnaire of this research consists of three parts:

Part I: Matters related to the implementation of sustainable agricultural practices

Part II: Includes an assessment of the factors affecting the implementation of sustainable agricultural practices, that it self consists of five parts as follows: 
- Areas related to economic factors affecting the implementation of sustainable agricultural practices.

- Areas associated with social factors affecting the implementation of sustainable agricultural practices.

- Areas related to policy-making factors affecting the implementation of sustainable agricultural practices.

- Areas associated with cultural factors affecting the implementation of sustainable agricultural practices.

- Areas associated with educational and promotional factors affecting the implementation of sustainable agricultural practices.

Part III: Includes personal and professional profile of individuals likeage, education, land ownership, and so on.

\section{Validity of the research tool}

In this research, for the nature and objectives of the study, the validity or validity of the questionnaire content has been investigated. To assess the validity of the research tools, a questionnaire was provided to the supervisors and consultants who, after examining and implementing the amendments, using the point of view of this the final questionnaire was completed and compiled.

\section{Reliability of Research Tool}

In order to achieve the reliability of the research tool, a preliminary test was conducted. In this test, the questionnaire was presented to and completed by about thirty members of the manufacturer. After collecting the questionnaires, the replies were summed up and evaluated. After extraction, the Cronbach's alpha coefficient was calculated for each section. The Cronbach's alpha coefficient in this questionnaire is shown separately in Table 1.

Table 1. Cronbach's alpha coefficient for the research questionnaire

\begin{tabular}{ccc}
\hline Questionnaire sections & $\begin{array}{c}\text { Number } \\
\text { of points }\end{array}$ & $\begin{array}{c}\text { Cronbach's } \\
\text { alpha } \\
\text { coefficients }\end{array}$ \\
\hline $\begin{array}{c}\text { Economic Factors Influencing Sustainable Agricultural } \\
\text { Operations }\end{array}$ & 8 & 0.946 \\
$\begin{array}{c}\text { Societal Factors Influencing Sustainable Agricultural } \\
\text { Operations }\end{array}$ & 6 & 0.739 \\
$\begin{array}{c}\text { Policy Factors Influencing Sustainable Agricultural Operations } \\
\text { Cultural Factors Influencing Sustainable Agricultural } \\
\quad \text { Operations }\end{array}$ & 6 & 0.794 \\
$\begin{array}{c}\text { Educational and promotional factors efficient in the } \\
\text { implementation of sustainable agricultural practices } \\
\text { Application of Sustainable Agricultural Operation }\end{array}$ & 8 & 0.741 \\
\hline
\end{tabular}

\section{Research Hypotheses}

First hypothesis - economic factors affect the implementation of sustainable agricultural practices. 
Second hypothesis - social factors have an impact on the implementation of sustainable agricultural practices.

Third hypothesis - Policy makers have an impact on the implementation of sustainable agricultural practices.

Fourth hypothesis- Cultural factors have an impact on the implementation of sustainable agricultural practices.

Fifth hypothesis - Educational and promotional factors affect the implementation of sustainable agricultural practices.

\section{Study of correlation among variables}

The results indicate that using sustainable agriculture with the variables of economic factors, policy factors and educational and promotional factors are significant at $1 \%$ level. So, with a confidence of 99 , there is a positive and significant relationship among the use of sustainable agriculture and the variables of economic factors, policy making factors and educational and promotional factors. The use of sustainable agriculture with variables of social factors and cultural factors has a significant level of 5\% too. So, with $95 \%$ confidence, there is a positive and significant relationship among the use of sustainable agriculture and the variables of social and cultural factors (Table 2).

Table 2. Correlation analysis among sustainable agriculture and impactive factors in sustainable agriculture

\begin{tabular}{ccc}
\hline independent variable & significance level & correlation coefficient \\
\hline Economic factors & 0.000 & $0.455^{* *}$ \\
Socialfactors & 0.011 & $0.252^{*}$ \\
Policy factors & 0.004 & $0.303^{* *}$ \\
Cultural factors & 0.026 & $0.225^{*}$ \\
Educational and & 0.0000 & $0.361^{* *}$ \\
promotional factors &
\end{tabular}

**: The significance level is $0.01^{*}:$ The significance level is 0.05

\section{Step-by-step regression analysis}

Multi-step regression method was used to analyze the role of variables of economic factors, policy factors, educational and promotional factors, social factors and cultural factors that have a significant relationship with the variable of applying sustainable agriculture. The results of the study indicated that among the independent variables that have a significant relationship with the dependent variable, three variables of economic factors, policy factors, educational and promotional factors are the most important independent variables affecting the dependent variable of sustainable agriculture, that is $42.1 \%$ of the variable variation Dependent research explains. Table 3 summarizes the regression model.

Table 3. Summary of the regression model

\begin{tabular}{lllll}
\hline Steps & independent variable & R & $\mathbf{R}^{\mathbf{2}}$ & $\mathbf{R}^{\mathbf{2} A d j}$ \\
\hline First Step & Economic factors & & 0.227 & 0.217 \\
Second Step & $\begin{array}{l}\text { Educational and promotional } \\
\text { factors }\end{array}$ & & 0.364 & 0.345 \\
Third Step & Policy factors & & 0.428 & 0.421 \\
\hline
\end{tabular}


In Table 4, the significance of the regression model of the $\mathrm{F}$ test has been investigated. Considering that the significance level calculated for this statistic in all steps is equal to 0.000 , it indicates that the regression model is significant at $99 \%$ level.

Table 4. ANOVA test for the significance of the regression model

\begin{tabular}{cccccc}
\hline Model & Mean square & $\begin{array}{c}\text { Degree of } \\
\text { freedom }\end{array}$ & RMS & F test & $\begin{array}{c}\text { Significance } \\
\text { level }\end{array}$ \\
\hline regression & 16.213 & 1 & 16.213 & 23.379 & 0.000 \\
remnant & 111.489 & 92 & 1.212 & & \\
Total & 127.702 & 93 & & & \\
regression & 20.936 & 2 & 10.468 & 18.922 & 0.000 \\
remnant & 106.766 & 91 & 1.173 & & \\
Total & 127.702 & 93 & & & \\
regression & 25.441 & 3 & 8.724 & 11.503 & 0.000 \\
remnant & 102.261 & 90 & 0.986 & & \\
Total & 127.702 & 93 & & & \\
\hline
\end{tabular}

According to other results of multiple regression analysis, it can be seen that the variable of economic factors with the standard beta coefficient of 0.339 has an efficient role on the dependent variable in the use of sustainable agriculture and has a significant predictive power for this variable.

The variable of educational and promotional factors with a standard beta coefficient of 0.264 , has an efficient role in the dependent variable in the use of sustainable agriculture.

The variable of policy making factors with the standard beta coefficient equal to 0.146 has an efficient role in the dependent variable in the use of sustainable agriculture.

Table 5. Regression coefficients of the research variables in the regression model

\begin{tabular}{|c|c|c|c|c|c|c|}
\hline \multirow{2}{*}{ Step } & \multirow{2}{*}{ Variable } & \multicolumn{2}{|c|}{$\begin{array}{l}\text { Non standardized } \\
\text { coefficients }\end{array}$} & \multirow{2}{*}{$\begin{array}{c}\text { Standardized } \\
\text { coefficients } \\
\text { Beta }\end{array}$} & \multirow{2}{*}{$\mathbf{t}$} & \multirow{2}{*}{ Sig. } \\
\hline & & B & $\begin{array}{l}\text { Std. } \\
\text { Error }\end{array}$ & & & \\
\hline \multirow{2}{*}{ First } & Width from origin & 0.802 & 0.105 & - & 7.666 & 0.000 \\
\hline & Economic factors & 0.455 & 0.038 & 0.419 & 18.854 & 0.000 \\
\hline \multirow{3}{*}{ Second } & Width from origin & 0.495 & 0.104 & - & 4.764 & 0.000 \\
\hline & Economic factors & 0.414 & 0.053 & 0.422 & 7.829 & 0.000 \\
\hline & $\begin{array}{l}\text { Educational and promotional } \\
\text { factors }\end{array}$ & 0.325 & 0.055 & 0.413 & 7.659 & 0.000 \\
\hline \multirow{4}{*}{ Third } & Width from origin & 0.460 & 0.105 & - & 4.389 & 0.000 \\
\hline & Economic factors & 0.332 & 0.066 & 0.339 & 5.060 & 0.000 \\
\hline & $\begin{array}{l}\text { Educational and promotional } \\
\text { factors }\end{array}$ & 0.313 & 0.060 & 0.324 & 6.185 & 0.000 \\
\hline & Policy factors & 0.146 & 0.070 & 0.146 & 2.086 & 0.026 \\
\hline
\end{tabular}

According to the regression coefficient B and Beta and the fixed value gained from multiple regression analysis using the stepwise method, the regression equation of the research was gained as follows: 
$\mathrm{Y}=0.460+0.332 \mathrm{X}_{1}+0.313 \mathrm{X}_{2}+0.146 \mathrm{X}_{3}$

$\mathrm{Y}=0.339 \mathrm{X}_{1}+0.324 \mathrm{X}_{2}+0.146 \mathrm{X}_{3}$

\section{Conclusion}

The test result of the first hypothesis of research: economic factors with a regression coefficient of 0.339 , with $99 \%$ confidence, affect the implementation of sustainable agricultural practices; so, the hypothesis is confirmed. Economic factors have had the greatest impact on the implementation of sustainable agricultural operations. Moazzeni, Omidi Najaf Abadi and Farajollah Hosseini (2014), Lashgar Araa Asadi (2009), Mohammadi, Farajollah Hosseini (2014), Motiyee Langroudi et al., (2009), Najafi and Zahedi (2005), Emeka William (2015) and Kinioroska and Kiczor (2012) has confirmed the role of economic agents in the implementation of sustainable agricultural practices in their research.

The test result of the second hypothesis of research: Social factors did not have a significant effect on the implementation of sustainable agricultural activities, and so the above rule is rejected.

The test result of the third hypothesis of research: policy making factors with a regression coefficient of 146/0, with 99\% confidence, affect the implementation of sustainable agricultural practices; so, the hypothesis is confirmed. Shayan et al., (2009), Talebi Fard and Talebi Fard (2013), Hasan Shahi et al., (2009), Najafi and Zahedi (2005), Nubutaka (2009) Pretty et al., (1992), Gimire (2002), Longpichai (2012) confirmed their role as policy makers on the implementation of sustainable agricultural practices.

The test result of the forth hypothesis of research: Cultural factors do not have a significant effect on the implementation of sustainable agricultural activities, and so the above-mentioned solution is rejected.

The test result of the fifth hypothesis of research: Educational and promotional factors with a regression coefficient of 0.342 have a $99 \%$ confidence in the implementation of sustainable agricultural practices; so, the hypothesis is confirmed. Enayatiraad et al., (2009), Ajili et al., (2009), Bagheri and Shah Pasand (2010), Sharifi et al., (2011), Talebi Fard and Talebi Fard (2013), Bigdeli and Sedighi (2010), Pretty et al., (1992), Sabarata and Sabayasachi (2013) and Longpichai (2012) in their research have confirmed the role of educational and promotional factors on the implementation of sustainable agricultural practices.

\section{Research suggestions}

Considering the role of economic factors in the implementation of sustainable agricultural practices is suggested:

- $\quad$ Considering the importance of supporting and providing financial incentives for sustainable agriculture, offering subsidies to producers of marginal products, providing cash subsidies to farmers, guaranteeing low-income products by the Rural Cooperative Organization of the country and providing appropriate insurance services to farmers.

- $\quad$ Given the importance of financial support for purchasing equipment for sustainable agriculture, promotion of access to bank credits, especially low-cost and subsidized loans for farmers, is recommended. Easy and quick access to credits is one of the prerequisites for 
the development of agricultural activities. Because, on the one hand, farmers and agricultural activists are not able to invest heavily for low incomes and high production costs; on the other hand, the private sector does not have much interest in investing in agriculture. Agricultural revenues increase the productivity of production factors, Eliminating the farmers 'cost of spending on adopting and applying new technologies, improving production conditions and increasing farmers' incomes. The Agricultural Bank, as the main trustee of paying agricultural facilities, can partner with other institutions, like the Agricultural Jihad, to identify target groups and, according to the priority of these groups, to pay cheap and urgent facilities.

- $\quad$ Considering the importance of establishing domestic markets for low-input and organic products for sustainable agriculture, market regulation and reforming the distribution and marketing structure of organic and non-organic products, as well as the development of exports of organic products and agricultural products derived from these products for the aim of improving foreign markets;

\section{Considering the role of educational and promotional factors on the implementation of sustainable agricultural practices, it is suggested}

- Considering the importance of using skilled and knowledgeable promoters in the use of sustainable agriculture, it is suggested that a workshop for the promotion of sustainable agriculture education and continuous in service be provided to policymakers, researchers, promoters and promotion experts in relevant organizations. By promoting the knowledge of the propagandists, more incentives for farmers in the necessity of implementing sustainable agricultural operations could be convinced and convinced of the importance of implementing it.

- Considering the importance of encouraging farmers to participate in training and promoting the implementation of sustainable agricultural practices in the use of sustainable agriculture, raising awareness of farmers can be carried out through the use of extensible brochures, television, radio and other means of communication and educational classes, etc. It was vital to educate and promote agricultural sustainability. The use of sustainable farming patterns in all villages is recommended too.

- Considering the importance of the contact of farmers with the promotion centers in the use of sustainable agriculture, it is suggested that with the help of the promotion agents in the region, appropriate information resources are developed to enable farmers to be integrated into new information and technologies. Public media and extensions brochures will be useful too.

- Implementing community education for villagers, including farmers, women and youth, and the training to attract all groups and interest and participation.

-Collaboration among the Ministry of Agriculture and Health and the collaboration among researchers with various agricultural and health expertise to educate villagers.

\section{Considering the role of policy factors in implementing sustainable agricultural practices, it is suggested}

- Considering the importance of granting the vital facilities for sustainable agriculture, encouraging the creation of financial and investment organizations in the agricultural sector to provide liquidity needed for production, as well as the proposed payment of small credits. For its high risk-taking nature, the agricultural sector is dependent on government 
direct investment and cost-injection. In rural and agricultural development, one of the solutions to financial problems faced by farmers is the granting of small scale credits that play an important role in concentrating and directing farmers' small investments.

- Given the importance of government support for Organic products in the use of sustainable agriculture, it is suggested that government policies and policies be taken to support the development and implementation of sustainable agricultural operations throughout the country, and since sustainable agriculture is an international issue today, this The rules are according to global experiences and their integration into national and local conditions.

- Considering the importance of reducing the prices of domestic bio-fertilizers for sustainable agriculture, targeting subsidies for chemical fertilizers and promoting the use of biological fertilizers, supporting the government to reduce the price of fertilizers and increasing customs tariffs for pesticides and fertilizers in order to prevent unregulated imports it is suggested. The production of organic products requires special inputs, including organic fertilizers, organic pesticides, and non-chemical tools for treating diseases and infections. The production, supply and supply of these inputs, in addition to its technical and specialized staff, require a large amount of funding and facilities that, with only austere determination, is possible to formulate and implement a specific and long-term program as well as comprehensive support. Farmers who, by choosing the route of organic produce, lose part of their product for the lack of use of chemical inputs and are willing to sacrifice the quantity for quality and provide healthy and clean food to the community mutually expected, the government will provide them with subsidized and inexpensive inputs.

- It is important to use the experiences of leading countries in the field of sustainable agricultural development plans.

- Development and implementation of public awareness programs for sustainable agriculture development.

- Manage capacity building and empowerment programs for the utilitarian community and private and local sectors for active participation in sustainable agricultural development plans.

- Before any action is taken to achieve sustainable agricultural development, all the custodians and the organizations involved in the task and tasks of each one must be identified. This step involves the achievement of a cooperation document at the level of government agencies to guide the implementation of these issues at this level and to determine the structure of the process.

- The full implementation of the sustainable agricultural development process requires adequate opportunity and timetable and should avoid any unnecessary and irrational imposition to speed up the process.

- Research on the sustainable development of agriculture will become a national imperative and specific budgets will be considered for development and research.

- According to the role of non-governmental organizations in the sustainable development of agriculture, they should take special measures to expand and empower them by removing legal gaps and facilitating their participation with the government. 


\section{References}

Goossens, SK, Matinfar, R, Mohamad, HR, Ghaderi, H, Irannegad, M, Alikhah Asl, H. (2008). The Efficiency of Landsat TM and ETM+ Thermal Data for Extracting Soil Information in Arid Regions. J. Agric. Sci. Technol., 10:439-460.

Bagheri, A, Shahspand, MR. (2010). Study on the Attitude of Ardabil Plain Farmers on Sustainable Agricultural Operation, Iran. J. Agricul. Econom. Res., 4(2):242-231.

Bigdeli, A, Sedighi H. (2010). Investigating the acceptance behavior of sustainable farming methods by extension workers in Qazvin province, Journal of Agricultural Economics and Development Research, Vol 41, Issue 3, Pages412-405.

Browne, MW, Cudeck, R, (1993). Alternative Ways of Assessing Model Fit, In: "Testing Structural Equation Models",(Eds.): Bollen, K. A. and Long, J. S. Newbury Park, Sage, CA, PP. 445-455.

Brugmann, J. (1997). Is There a Method in Our Measurement? The Use of Indicators in Local Sustainable Development Planning. Local Environ., 20(1):59-72

Davoodi, H, Maghsoudi, T. (2010). A Study of Sustainable Agricultural Knowledge among Potato Masters of Shoushtar, Iran J. Agricul. Econom. Develop., 42(2):264-256.

Enayati Rad Mandana et al. (2009), Factors Affecting the Knowledge of Corn Farmers on Sustainable Agriculture in the Northwest of Khuzestan, Science and Promotion of Iranian Agriculture Education, Vol 5, No 2.

McCool, DK, Huggins, DR, Saxton, KE, Kennedy, AC. (2001). Factors Affecting Agricultural Sustainability in the Pacific Northwest, USA.

Factors affecting sustainability of Agricultural Cooperatives, 2011. Agnes Towera Nkhoma

Factors affecting sustainable agricultural productivity in Ebonyi State, Nigeria.2015EGWU, Emeka Williams

Factors affecting sustainable development of Agriculture and Rural Areas in the Vivodship. Iwonakiniorska, WronskaKiczor.

Leading, H, Azizi, P. (2009). Sustainable Agricultural Development through Sustainable Agricultural Income, Journal of Human Geography, First Year, No. 4.

Shayan Hamid et al. (2012), The Role of Culture in Sustainable Agricultural Rural Areas, National Conference on Rural Development, Ferdowsi University of Mashhad.

Macrae, RJ, Henning, J, Hill SB. (1993). Strategies to Overcome Barriers to the Development of Sustainable Agriculture in Canada, J Agricul Environ Ethics, 6(1):21-51.

Asadi, A, Kalantari, K, Choobchian, S. (2013). Structural Analysis of Factors Affecting Agricultural Sustainability in Qazvin Province, Iran, J Agricul Sci Technol, 15(1):11-22. 
Bosshaq, MR, Afzalinia, F, Moradi H. (2013). The role of impactive factors in sustainable agricultural system-A case study of Minudashat in Iran, Int J Agri Sci, 2(6):550-557.

Zare Feizabadi, A, Kouchaki, A. (1997), Reviewing of the Process of Changing Research Projects on Sustainable Agriculture, Agricul Econom Develop, No. 17.

How to cite this article: Tahmineh Toliatkashani, Maryam Omidi Najaf Abadi, Farhad Lashgarara, Factors Affecting the Use of Sustainable Agriculture in Iran's Potato Cultivars. International Journal of Advanced Biological and Biomedical Research, 2019, 7(3), 213-224. Link: http://www.ijabbr.com/article 34757.html 